\title{
Влияние занимательных опытов кружковой деятельности по физике на уровень креативности
}

\author{
Прядезникова А.А., студент, \\ Северо-Восточный федеральный университет, \\ 2. Якутск \\ E-mail: AilitaVinokurova@mail.ru
}

Научный руководитель: стариий преподаватель Карпова Е.В.

Задача преподавания физики не может ограничиваться сообщением учащимся только тех знаний, содержание и объем которых указываются официальной программой по физике. Все запросы учащихся должны оказаться в посильной мере удовлетворенными. Так как время, отведенное для уроков, должно быть использовано только по своему прямому назначению, то для удовлетворения этих запросов следует организовать кружковые работы. [1, стр. 298]

Значение кружковой работы по физике - повысить у учащегося креативные умения, техническую изобретательность и воспитать творческую личность, чтобы высшая школа смогла подготовить из него компетентного специалиста, обладающего нравственной и духовной культурой.

Педагог должен в полной мере понимать, что в основе любой деятельности лежат мотивы, которые стимулируют ученика, подталкивают его к новым знаниям. Механизм формирования мотивов связан с осознанием потребностей, приданием им личностного смысла. Таким образом, между высокой общественной значимостью результатов креативной деятельности и самим процессом создания креативного продукта оказываются мотивы. На практике креативность сводится к подражанию творчеству, зачастую, минуя творческий процесс, человек может создавать креативные продукты и развивать креативные качества. Следует согласиться с мнением В.Н. Дружинина, отметившего, что “формирование креативности как личностной характеристики сначала проявляется на мотивационно-личностном, затем на продуктивном (поведенческом) уровне” [2, стр. 76].

В.Н. Дружинин считает, что креативность является свойством, которое актуализируется лишь тогда, когда это позволяет окружающая среда. Для формирования креативности необходимы следующие условия:

1) отсутствие образца регламентированного поведения;

2) наличие позитивного образца творческого поведения (в первую очередь на развитие способности влияет общение детей со взрослыми людьми, обладающими развитыми креативными способностями);

3) создание условий для подражания творческому поведению;

4) социальное подкрепление творческого поведения.

В процессе создания креативного продукта происходит актуализация личностного знания, и присвоение общественного знания путем превращения этого знания в личностное, и создание нового знания, которое может быть личностно значимым или общественно значимым в зависимости от степени новизны, ее ценности для общества, науки, техники.

Формирование и развитие креативного мышления 
Наиболее подходящей областью для формирования креативного мышления является занимательные опыты по физике, так как здесь, главным образом, путем креативно-технических экспериментов, можно с раннего возраста воспитывать самостоятельность мышления. Физика гораздо ближе и к жизни, и к возможностям научного изучения процессов в окружающей нас природе, тем более что с помощью экспериментально-демонстрационных опытов школьник учится из наблюдений выводить теоретические обобщения. Во время кружка можно показывать, как противоречие между теоретическими представлениями и экспериментом приводит в физике к новым научным открытиям. Большую пользу для развития креативного мышления в физике приносят занимательные опыты, которые позволяют наиболее эффективно выявлять творческие способности юношества.

Значение и содержание кружка занимательной физики. Кружок занимательной физики организуются с тем, чтобы возбудить или повысить интерес к физике и, пользуясь этим интересом, расширить и пополнить знания учащихся. Такие кружковые работы рационально организовывать одновременно для нескольких одинаковых классов, т. е. с 7 - 9 классы.

Одним из признаков занимательности является чувство удивления, возникающее при ознакомлении с опытом, задачей, картинкой и т. п. Удивление же в свою очередь вызывается совершенно необычной (парадоксальной) постановкой вопроса или опыта или полной неожиданностью развития процесса, или же, наконец, получаемого результата.

На кружке возможно применение следующих форм работы:

- $\quad$ Парадоксы.

- $\quad$ Опыты на предметах обихода.

- $\quad$ Занимательные положения.

- $\quad$ Картины занимательного характера

1) П а р ад о к сы . Занимательность, как это было уже выяснено, в основном определяется необычностью наблюдаемого физического явления или неожиданностью результата, приводящими к возникновению чувства удивления. Необычность же явления или неожиданность результата может быть осознана учащимися, когда наблюдаемые процессы оказываются в полном противоречии по. отношению к логике знаний учащихся. Таким образом, необходимым условием для восприятия необычного и неожиданного является запас некоторых определенных знаний. Так, например, если учащимся известно, что стекло является непроводником, то демонстрация опыта ионной проводимости стекла поразит учащихся. При отсутствии же знаний об изоляторах этот опыт не может произвести глубокого впечатления.

Из сказанного следует, что некоторые из обычных физических опытов, воспроизводящих такие явления, которые оказываются в противоречии со знаниями учащихся, могут быть с успехом показаны на кружке занимательной физики. Количество таких опытов весьма значительно. К числу их можно, например, отнести: некоторые опыты по молекулярным явлениям (вода в решете, мыльные пленки, опыты с поверхностным натяжением, плавание иголки на воде и т. и.), вода в перевернутом стакане, «тяжелая газета», «водяной холм», «огнеустойчивый воздушный шар», «лава в бутылке» и т. п.

При подборе таких опытов надо иметь в виду, чтобы объяснения демонстрируемых физических явлений оказались доступными для учащихся и демонстрация не свелась лишь к одному занимательному зрелищу [3. стр.75]. 
2 ) О п ы ты н а п р е д е т а х о б и х о да . Занимательность опытов может быть создана применением для воспроизведения физических явлений предметов, имеющих совершенно иное назначение. Так, предметы обихода: ложка, блюдце, ножик, вилка, половая щетка, стул, картошка, яйцо, наперсток, иголка и т. п., при демонстрации некоторых, правда, немногих, физических явлений могут с успехом заменить обычно применяемые для этого приборы. Обильный материал по использованию предметов бытового характера для демонстрации можно найти в классических книгах по научным развлечениям Тома Тита. Такие опыты, как показывает практика, производят на учащихся сильное впечатление и обычно повторяются ими в домашних условиях.

3) 3 ани м ательны е положения. Невозможность для человека совершить некоторые движения: встать со стула, поднять предмет с пола при определенном положении центра тяжести - может демонстрироваться на кружке.

4) К а р тины 3 ан и м а те льного х а ра к т е а . Значительный интерес возбуждает демонстрация различного рода картин, содержащих в себе головоломки физического характера, ребусы, кроссворды и т. п. Силами учащихся могут быть выполнены картины, копируемые с оригинала. Рационально некоторые из картин рисовать тушью на стекле и проектировать на экран [4. стр. 38].

\section{Оценка уровня креативности}

Для оценки уровня креативности по всем критериям ученикам даются задания, включающие выполнение физических опытов, изготовление макетов из подручных средств, сборки установок.

Эти задания предполагают наличие у учащихся сообразительности, воображения, смекалки и других качеств креативности. При выполнении опытов у учеников есть полное свобода действий, своего рода карт бланш, но с ограничением подручных средств и в итоге должен получится правильный, рациональный и оригинальный результат.

Уровень креативности определялся следующим образом:

III - высокий уровень ставится в том случае, если учащийся самостоятельно, творчески и рационально смонтировал необходимое оборудование, все опыты провел в условиях, обеспечивающих получение правильных и оригинальных результатов и выводов; соблюдал требования безопасности труда, выполнил работу в полном объеме с соблюдением необходимой последовательности проведения опытов и измерений; в отчете правильно и аккуратно выполнил все записи, таблицы, чертежи, графики, вычисления.

II - средний уровень ставится в том случае, если учащийся допустил недочеты или негрубые ошибки.

I - низкий уровень ставится, если учащийся не достиг поставленных целей.

\section{Заключение}

Занимательные физические опыты сподвигают учащихся к новым знаниям, формируют креативное мышление, повышают техническую изобретательность. Исходя из этого нужно подчеркнуть, что необходимо организовать кружковую деятельность по физике с упором на то, чтобы у учеников была свобода действий и самостоятельность при проведении опытов. Так же выполнение демонстрационных, экспериментальных и занимательных опытов разрешается и даже приветствуется группой из двух-трех учеников. Коллективное творчество учащихся способствует формированию у них коммуникативной, социально-информационной и персональной ключевых компетенций; воспитывает чувства коллективизма, ответственности. 


\title{
Список литературы:
}

1. Прядезникова А.А., Карпова Е.В. Организация кружковой работы в обучении физике/ Материалы XVII Всероссийской научно-практической конференции молодых ученых, аспирантов и студентов в г. Нерюнгри, с международным участием, посвященной 60-летию со дня образования Якутского государственного университета (СВФУ).// - Нерюнгри : Изд-во Технического института (ф) СВФУ, 2016. - С. 89-93

2. Дружинин В.Н. Психология общих способностей. СПб., 1999.

3. Елкин В.И. Необычные учебные материалы по физике: Задачи, тесты, практические работы, книжка для чтения и раздумий / Сост Э.М. Браверман. - М.: Школа-Пресс - 2011. - 80 с.

4. Елкин В.И. Оригинальные уроки физики и приемы обучения / Сост Э.М. Браверман. - М.: Школа-Пресс - 2011. - 80 с.

\section{Подходы к обучению работников Навоийского ГМК}

\author{
Ражаббоев И.М., научный сотрудник, \\ Навоийский государственный горный институт, \\ 2. Навои, Узбекистан \\ E-mail: u0505@mail.ru
}

Научный руководитель: к.т.н. Шарафутдинов У.З.

В Национальной программе по подготовке кадров Узбекистана указывается не только на потребность в реформах в области образования, но и методах применения современных технологий в процессе обучения и переподготовки кадров на производстве.

Главным показателем уровня квалификации современного специалиста является его профессиональная компетентность. Компетентность предполагает постоянное обновление знаний, владение новой информацией дли успешного решения профессиональных задач в данное время и данных условиях. Сегодня стало повседневно практикой, когда в процессе обучения применяются современные информационнокоммуникационные технологии. Существующие методы визуального программирования позволяют создавать электронные образовательные средства и применять их при обучении работников промышленности. Эго приводят к необходимости широкого использования новых подходов к организации учебного процесса, применения различных педагогических форм и методов обучения

Наибольший эффект применения новых информационных технологий в образовательном процессе достигается при использовании информационных и демонстрационных программ, модулирующих программ, обеспечивающих интерактивный режим работы обучаемого с компьютером, экспертных систем для диагностики уровня обученности, доступа к информационным ресурсам сети Интернет.

Преподаватель получает дополнительные возможности для поддержания и направления развития личности обучаемого, творческого поиска и организации их совместной работы, разработки и выбора наилучших вариантов учебных программ. Появляется возможность освобождения от свойственных обучению рутинных видов деятельности преподавателя, предоставления ему интеллектуальных форм труда. 